\title{
Enhanced Recovery Program after Cesarean Section in Sulaimani Maternity Teaching Hospital
}

\author{
Savinaz Abubakir Mohammed \\ Department of Gynecology and Obstetrics \\ Sulaimani Maternity Teaching Hospital \\ Sulaimani, Iraq \\ safinaz.abubakir@gmail.com
}

\author{
Srwa Jamal Murad \\ College of Medicine \\ University of Sulaimani \\ Sulaimani, Iraq \\ srwa.murad@univsul.edu.iq
}

\author{
Ariana Khalis Jawad \\ Department of Gynecology and Obstetrics \\ Hawler Medical University \\ Hawler, Iraq \\ aryianadr@yahoo.com
}

\begin{tabular}{l} 
Article Info \\
Volume 5-Issue 1- \\
June 2020 \\
DOI: \\
10.24017/science.2020.1.20 \\
Article history: \\
Received: 09 April 2020 \\
Accepted : 25 June 2020 \\
\hline
\end{tabular}

Keywords:

Cesarean delivery,

Elective cesarean section,

Enhanced recovery program,

Fast-track surgery.

\begin{abstract}
Enhanced recovery program (ERP) for cesarean section $(C / S)$ is improving patient health and is cost-effective for healthcare providers. We aimed to assess how ERP improves patient satisfaction, ambulation time, severity of pain, decrease hospital stay among patients attending Sulaimani Maternity Teaching Hospital and fetal outcome. A quasi-experimental study was performed on 200 patients in Sulaimani from June 2019 to December 2019. The participants divided into two equal groups. The intervention group was 100 women who underwent elective C/S in Sulaimani Maternity Teaching Hospital and subjected to ERP. While the control group was the other 100 women who were not subjected to the ERP, and they were from the Emergency Department of the same hospital. The women in the intervention group were supervised by anesthetists from preoperatively, intraoperatively, through postoperatively. The intervention group showed significantly better outcome regarding time to ambulate; all patients were able to ambulate 45 hours postoperatively. Also, the duration of hospital stay was better in the intervention group; all the patients discharged before 24 hours, but five patients in the control group discharged after 24 hours. Besides, fetal Apgar score after five minutes was also better in the intervention group; at the first minute, the mean $\pm S D$ (standard deviation) of Apgar score was $8.36 \pm 1.38$ and $8.08 \pm 1.69$ for the intervention, and control groups, respectively (P-value $=0.2)$. While at five minutes, the mean $\pm S D$ of Apgar score was 9.59 \pm 064 , and $8.96 \pm 1.12$ for the intervention, and control groups, respectively $(P$-value $=$ $<0.001)$. This intervention had favorable outcomes regarding pain, time of ambulation, and fetal Apgar score. We recommend implementing ERP at a broader scale as it gives better outcomes.
\end{abstract}

Copyright () 2020 Kurdistan Journal of Applied Research. All rights reserved. 


\section{INTRODUCTION}

A natural event of women's life is childbirth. Childbirth is associated with emotional and physical changes; therefore, cesarean section $(\mathrm{C} / \mathrm{S})$ is a surgical procedure that changes the mother and baby interaction of the postpartum period into the postoperative period [1].

The C/S is one of the most common surgeries performed in the United States; about one-third of childbirth (nearly 1.3 million annually) is performed by C/S [2-3]. In Canada, the rate of C/S was increased from $17 \%$ of all births in 1995 to $29 \%$ in 2010-2011 [3]. Besides, in France, $21 \%$ of annual deliveries (about $160000 \mathrm{C} / \mathrm{Ss}$ ) were performed by C/S [4]. Thus, C/S is a common procedure and public health challenge [4]. Therefore, the recovery principles applied to $\mathrm{C} / \mathrm{S}$ require effective collaboration between non-medical and medical teams who are caring for the mother and newborn [4].

The main concern for the women who are undergoing $\mathrm{C} / \mathrm{S}$ is postoperative pain, which causes distress and compromises early mother and baby interaction and delay recovery [1]. Nowadays, about $12 \%$ of the patients who are undergoing surgeries still suffer from severe pain after discharge from the hospital [1]. Good management of pain can improve the mother and baby bonding. Physical contact between the mother and the baby during childbirth is essential for the development of this bonding [5].

The idea of the enhanced recovery program (ERP) after the surgery was emerged more than 15 years ago [6-7]. This program is also known as fast-track surgery [6-7]. The ERP is a standardized interdisciplinary and evidence-based approach involving nursery teams, surgeons, anesthesiologists, and postpartum teams, to improve the care of patients who are undergoing surgeries $[2,8]$. The ERP is not only for humanistic purposes, but it is also used for economic purposes [1, 3, 8-9]. When ERP is combined with an audit system and multidisciplinary team, it results in the reduction of surgical stress, enhances physiological and functional recovery, and decreases hospital stay, rapid return to regular activity, and fewer complications [3, 8-9]. Therefore, ERP has a triple aim; improving quality of care, increase patient satisfaction, and decreasing the costs [10].

The purpose of the program is to optimize patients' perioperative care by accelerating the patients' recovery to normal physiological state [6-7, 11-12]. Also, the ERP pathway is the concept of enhancing and improving recovery from the catabolic and inflammatory body responses to surgery [2]. Further, this program had been used for patients who underwent colorectal surgeries; however, the same idea had also been used in general surgery, breast surgery, urology, orthopedics, and gynecological oncology and general gynecology [2-3, 6, 12]. However, its implementation was slower in obstetrics despite the increasing numbers of C/S performed each year [7]. In theory, many elements of ERP could apply to obstetrical surgeries as in the major surgeries involving the abdomen [3].

Although there are some limitations to early discharge in obstetrics, including maternal acceptability, concerns about neonatal safety and establishment of breastfeeding, the National Institute for Health and Care Excellence (NICE) had integrated ERP into its guidelines [6-7]. The NICE stated if a woman after $\mathrm{C} / \mathrm{S}$ recovered well and did not have complications can be offered an early discharge from the hospital within 24 hours and looked after at home [2, 13].

The women after $\mathrm{C} / \mathrm{S}$ without the application of this program are usually discharged home at least two to three days postoperatively [6-7]. However, the women will be discharged home within 24 hours after the C/S if the program was implemented [6-7]. Thence, it results in a significant saving of the costs due to bed occupancies, delayed starting time and postponement of delivery for some subsequent elective C/Ss, and limiting the availabilities of healthcare $[2$, 6-7].

The ERP had created a maternal focused pathway from 30-60 minutes before skin incision to the time of maternal discharge $[8,11]$. Its components are including preoperative, intraoperative, and postoperative elements [7, 14]. Moreover, the preoperative elements are fasting periods of at least six hours before the surgery; clear fluids for up to two hours before surgery including oral carbohydrate fluid drinks women without diabetes mellitus, i.e., providing a preoperative carbohydrate load, prophylactic antibiotics, premedication with an 
antacid and histamine 2 (H2) receptor antagonist, and skin preparation with chlorhexidinealcohol is preferred over povidone-iodine [2, 7-8, 14]. However, cleansing of the vagina with povidone-iodine is protective against surgical site infection [8]. Besides, the intraoperative elements are anesthetic managements, prevention of hypothermia, ensuring euvolemia, and surgical technique [7, 14]. The postoperative elements are chewing gums, management of nausea and vomiting, multimodal analgesia to control postoperative pain, and management of fluid and blood pressure, early oral intake, tight control of blood glucose, early removal of a foley catheter, drain and intravenous cannula, early patients mobilization, and breastfeeding, and antithrombotic prophylaxis [2, 4, 7-8, 14]. Neonatal care is another elements of postoperative in ERP and should be commenced with delaying cord clamping; at least 30 seconds for preterm baby and one minute at term, maintaining the body temperature of the newborn between $36.5^{\circ} \mathrm{C}$ and $37.5^{\circ} \mathrm{C}$, and resuscitation in room air immediately [8].

Analgesia is the main principle of ERP after $\mathrm{C} / \mathrm{S}$, and a multimodal approach to the management of pain is needed in order to limit the use of opioids [9, 15]. Neuraxial analgesia, such as spinal or epidural analgesia, can reduce pain in patients who are undergoing C/S [15]. Epidural or Subarachnoid morphine injection, despite its side effects such as nausea, vomiting, pruritus, urinary retention, sedation, and respiratory depression, is the gold standard for controlling postoperative pain after C/S [9, 15]. Also, a transversus abdominis plane block is another route of analgesia which associated with less gastrointestinal transit [9]. Besides, regularly scheduled administration of non-steroidal anti-inflammatory drugs, as well as paracetamol, anxiolytics, neuraxial analgesia, and regional nerve block, can help in controlling postoperative pain and limit the use of opioids $[8,15]$.

The study aimed to assess how ERP improves the patients' satisfaction, ambulation time, severity of pain, reduce hospital stay among patients who were undergoing C/S in Sulaimani Maternity Teaching Hospital and fetal outcome.

\section{PATIENTS AND METHODS}

A Quasi-experimental design was performed on 200 patients in whom they had either elective or emergency $\mathrm{C} / \mathrm{S}$ in Sulaimani, Kurdistan, Iraq. The participants divided into two equal groups; the intervention group was 100 women who underwent elective $\mathrm{C} / \mathrm{S}$ in Sulaimani Maternity Teaching Hospital and subjected to the ERP. While the control group was 100 women were not subjected to the ERP, and they were chosen from the Public Emergency Department of the same hospital. Besides, the study performed from June 2019 to December 2019.

The study was started after approval from the Ethical Committee of the Kurdistan Board of Medical Specialties (KBMS) and the directorate of the Sulaimani Maternity Teaching Hospital. Also, informed consent was taken from each participant after a full explanation.

Inclusion criteria were pregnant women who were undergoing $\mathrm{C} / \mathrm{S}$. The exclusion criteria were women who were suffering from significant medical comorbidities like diabetes mellitus and hypertension, and who were refusing to participate in the study.

The sociodemographic data of the patients were recorded. The patients in the intervention group fasted for seven to eight hours for solid food and two hours for clear fluid. Moreover, optimization of the hemoglobin level performed to reduce the risks related to anemia, such as delay recovery. Besides, a preload of 500-1000 ml crystalloid, vasopressors, Zantac ampoule, and thromboprophylaxis, were given. Furthermore, prophylactic antibiotics, and a low prophylactic dose of oxytocin infusion (10-15 units per hour), were given to all the patients in both groups.

Postoperative painkillers were given to the intervention group on a regular base during the first 12 hours and then given depending on the Visual Analogue Scale (VAS), a pain rating scale measured from zero (no pain) to ten (severe pain) [16-17]. Furthermore, the administration of painkillers started intraoperatively by infiltration of the incision by $0.5 \%$ Marcaine, i.e., field block. Then, two doses of indomethacin suppository were given; the first dose was given immediately after the surgery and the other after 12 hours. Also, injections of 
$50 \mathrm{mg}$ pethidine and Rolac ampoules - the first dose was given two hours after indomethacin, and the second dose was 12 hours later-, were performed. Concomitantly, paracetamol vial (one gram) was given two hours after Rolac ampoule and then every six to eight hours. Meanwhile, the pain of the patients in the control group was managed according to the routine practice of the hospital, depending on their need for painkillers.

All women in the intervention group were started oral fluid intake two hours after the C/S, early ambulation after four to five hours, initiation of breastfeeding, and removal of the urinary catheter after six hours. Besides, patients' satisfaction was measured numerically; least satisfaction was considered 22 and a satisfaction of 55 indicated the most satisfaction.

The "IBM SPSS Statistics version 25" was used for the analysis of the data, and both descriptive and inferential statistics were used. Furthermore, P-values of $(\leq 0.05$ and $<0.001)$ were considered as statistically significant, and highly significant associations, respectively. Also, Pearson Chi-Square was used to find out the significance of the association between categorical independent and dependent variable pairs, and the Student's T-Test was used to compare numerical independent and dependent variable pairs.

\section{RESULTS}

The ages of women in the intervention group were slightly older as compared to women in the control group. Besides, the majorities $(84 \%)$ of women in both groups were 25 years old and more; $44 \%$ in the intervention group as compared to $40 \%$ in the control group. Although these differences in ages between the groups were little, it was statistically significant difference (Table 1).

The majorities $(65 \%)$ of the patients were from Sulaimani center and there were not statistically significant differences among both the groups for residencies of the women (Table 1). Also, there was statistically non-significant difference for blood groups among both the groups and the majority of women were either group A $(33 \%)$ or group O $(30.5 \%)$ as shown in Table 1. Further, the majorities (84\%) of the women in both the groups were multiparous and the difference of gravidity among both the groups was statistically significant (Table 1).

Table (1): Sociodemographic features of the study participants

\begin{tabular}{|c|c|c|c|}
\hline Patient characteristics & Intervention group & Control group & p-value \\
\hline \multicolumn{4}{|l|}{ Age } \\
\hline $15-24$ years & $12(6 \%)$ & $20(10 \%)$ & \multirow{4}{*}{0.01} \\
\hline 25-34 years & $50(25 \%)$ & $61(30.5 \%)$ & \\
\hline$\geq 35$ years & $38(19 \%)$ & $19(9.5 \%)$ & \\
\hline Mean \pm SD & $31.9 \pm 5.7$ & $29.7 \pm 5.9$ & \\
\hline \multicolumn{4}{|l|}{ Residency } \\
\hline Sulaimani Center & $63(31.5 \%)$ & $67(33.5 \%)$ & \multirow{3}{*}{0.43} \\
\hline Territory & $36(18 \%)$ & $30(15 \%)$ & \\
\hline Other Governorates & $1(0.5 \%)$ & $3(1.5 \%)$ & \\
\hline \multicolumn{4}{|l|}{ Blood group } \\
\hline $\mathrm{A}^{+}$ & $26(13 \%)$ & $34(17 \%)$ & \multirow{8}{*}{0.18} \\
\hline $\mathrm{A}^{-}$ & $3(1.5 \%)$ & $3(1.5 \%)$ & \\
\hline $\mathrm{B}^{+}$ & $15(7.5 \%)$ & $15(7.5 \%)$ & \\
\hline $\mathrm{B}^{-}$ & $1(0.5 \%)$ & $4(2 \%)$ & \\
\hline $\mathrm{AB}^{+}$ & $6(3 \%)$ & $6(3 \%)$ & \\
\hline $\mathrm{AB}^{-}$ & $2(1 \%)$ & $0(0 \%)$ & \\
\hline $\mathrm{O}^{+}$ & $27(13.5 \%)$ & $31(15.5 \%)$ & \\
\hline $\mathrm{O}^{-}$ & $2(1 \%)$ & $1(0.5 \%)$ & \\
\hline \multicolumn{3}{|l|}{ Gravidity } & \multirow{2}{*}{$<0.001$} \\
\hline Primigravida & $3(1.5 \%)$ & $29(14.5 \%)$ & \\
\hline
\end{tabular}




\begin{tabular}{lll} 
Gravida $2-4$ & $80(40 \%)$ & $56(28 \%)$ \\
Gravida $\geq 5$ & $17(8.5 \%)$ & $15(7.5 \%)$ \\
\hline
\end{tabular}

$\mathrm{SD}=$ Standard deviation

All the women in the intervention group were started to ambulate after four to five hours, while all the women in the control group were ambulated after six hours; the differences between them were statistically significant (Table 2). Besides, although post C/S pain was more severe in the control group, but the difference was not statistically significant (Table 2). Furthermore, there was a statistically significant association among the groups and maternal hospital discharge; five patients in the emergency group discharged home after 24 hours (Table 2).

Table (2): Ambulation Time, the severity of pain measured by VAS, and hospital discharge time among both the groups

\begin{tabular}{lccc}
\hline \multicolumn{1}{c}{ Operation outcome } & Intervention group & Control group & p-value \\
\hline Ambulation Time & $100(50 \%)$ & $0(0 \%)$ & $<0.001$ \\
After 4-5 hours & $0(0 \%)$ & $100(50 \%)$ & \\
After 6 hours & $61(30.5 \%)$ & $52(26 \%)$ & 0.34 \\
\hline VAS & $36(18 \%)$ & $42(21 \%)$ & \\
$0-3$ & $3(1.5 \%)$ & $6(3 \%)$ & 0.02 \\
$4-6$ & $100(50 \%)$ & $95(47.5 \%)$ & \\
$7-8$ & $0(0 \%)$ & $5(2.5 \%)$ & \\
\hline Hospital discharge & & & \\
$<24$ hours & & & \\
$>24$ hours & & & \\
\hline
\end{tabular}

VAS $=$ Visual Analogue Scale

Our results showed a statistically insignificant association of both groups with patient satisfaction and pain scores (Table 3). In contrast, the association of APGAR scores in the fifth minutes with the groups was statistically significant (Table 3).

Table (3): Fetal APGAR score, Patients' satisfaction score and VAS for both the studied groups

\begin{tabular}{lccc}
\multicolumn{1}{c}{ Operation outcome } & $\begin{array}{c}\text { Intervention } \\
\text { group }\end{array}$ & Control group & p-value \\
\hline $\begin{array}{l}\text { APGAR Score ( first Minute) } \\
\text { (Mean } \pm \text { SD) }\end{array}$ & $8.36 \pm 1.38$ & $8.08 \pm 1.69$ & 0.2 \\
$\begin{array}{l}\text { APGAR Score (fifth Minute) } \\
\text { (Mean } \pm \text { SD) }\end{array}$ & $9.59 \pm 0.64$ & $8.96 \pm 1.12$ & $<0.001$ \\
$\begin{array}{l}\text { Patient Satisfaction Score (22 to 55) } \\
\text { Mean } \pm \text { SD }\end{array}$ & $45.47 \pm 4.89$ & $46.37 \pm 5.78$ & 0.24 \\
VAS (Mean \pm SD) & $2.97 \pm 1.62$ & $3.36 \pm 2.07$ & 0.14 \\
\hline SD = Standard deviation, VAS = Visual Analogue Scale & &
\end{tabular}

\section{DISCUSSION}

Child Birth is the most common indication for admission to the Sulaimani Maternity Teaching Hospital, and the most common surgery to help childbirth performed is C/S. Therefore, the ERP is a method of choice to be applied to improve patient outcomes and quality of care with the use of the evidence-based approach. According to the statistics department of the Sulaimani Maternity Teaching Hospital, 4313 (32.88\%) out of the total of 13119 birth in 2018 were delivered by $\mathrm{C} / \mathrm{S}$, which is a remarkable portion of total annual births.

In the current study, the majorities of women were aged 25-34 years old and were multiparous; $55.5 \%$ and $84 \%$, respectively (Table 1). These findings were slightly different in 
the literature that may be due to the differences between the social customs and norms among the studied populations. For example, the majorities of women in the study of A. Kett et al. [18] were aged 20-30 years and were primiparous. In comparison, the majorities of women were 30-39 years old and multiparous in the study of E. Enabudoso et al. [19].

Although the mean \pm SD score of the pain rating scale (VAS) was lower in the intervention group $(2.97 \pm 1.62$ and $3.36 \pm 2.07$ for intervention and control groups, respectively), it was not statistically significant (Tables 2 and 3). It was because most of the emergency patients of the control group underwent a trial of vaginal delivery and then followed by the C/S. Moreover, we used a pain scale from zero to 10 and were assessed at two, six, and 12 hours after surgery. While in the study of L. Renfro et al. [16], the patients were assessed at rest, six, $12,18,24,30,36,42$, and 72 hours, although they used the same VAS. Furthermore, our study is similar to the study of L. Renfro et al. [16], who involved a multi model pain regimen that initiated immediately after the delivery of the baby. It was also similar to the study of I. Veličković et al. [20] in their multi-model approach to pain control.

All of our elective patients in the intervention group were discharged from the hospital in less than 24 hours, but five $(2.5 \%)$ of our emergency patients in the control group were discharged after 24 hours (Table 2). The study of N. C. Teigen et al. [21] also found that ERP was associated with significantly decreased postoperative hospital stay when compared with standard care (median length of stay of 73.5 hours vs. 75.5 hours from surgery, respectively). However, G. A. Macones et al. [22] found a non-significant reduction in the length of stay between the two groups.

In the current study, the patient's satisfaction score ranged from (22 to 55) with a score of 22 being very dissatisfied and was considered the lowest score, and a score of 55 was the highest score and represented very satisfied. Besides, the mean \pm SD of satisfaction scores in our study were $45.47 \pm 4.89$ and $46.37 \pm 5.78$ for the intervention and control groups, respectively (Table 3). In contrast to our study, in the study of E. Enabudoso et al. [19], the satisfaction with cesarean deliveries was higher among women who had elective cesarean deliveries as compared with emergency cesarean deliveries. These differences in our study may be due to that, although the patients who were undergoing elective C/S were counseled over time, psychologically prepared, and they knew the reason for surgery, their expectation was high. While the patients in the control group who suffered more during the emergency situations that they had, they expected less than the prepared patients for elective C/Ss who had had high expectations.

In the current study, the removal of the foley catheter was after six hours for all the patients in both intervention and control groups. In contrast, in the study of I. Veličković et al. [20], the urinary catheter was removed at least after the first postoperative day.

\section{CONCLUSION}

The ERP is a critical program to be applied for early hospital discharge after cesarean deliveries because it reduces the cared burden and costs for obstetrical units.

Our main limitation was difficulties in choosing much identical control group due to the limited time and the responsibilities of intervention. Therefore, we recommend performing same intervention and comparing the results to much identical groups of elective cases.

\section{REFERENCE}

[1] P. Lavand'homme, "Postoperative cesarean pain: real but is it preventable?", Curr Opin Anaesthesiol, 31(3), pp. 262-267, 2018.

[2] E. E. Fay, J. E. Hitti, C. M. Delgado, L. M. Savitsky, E. B. Mills, J. L. Slater, et al., "An enhanced recovery after surgery pathway for cesarean delivery decreases hospital stay and cost", Am J Obstet Gynecol, 221(4), pp. 349.e1-349.e9, 2019.

[3] J. Huang, C. Cao, G. Nelson, R. D. Wilson, “A Review of Enhanced Recovery After Surgery Principles Used for Scheduled Caesarean Delivery”, J Obstet Gynaecol Can, 41(12), pp. 1775-1788, 2019. 
[4] B. Deniau, N. Bouhadjari, V. Faitot, A. Mortazavi, G. Kayem, L. Mandelbrot, et al., "Evaluation of a continuous improvement programme of enhanced recovery after caesarean delivery under neuraxial anaesthesia", Anaesth Crit Care Pain Med, 35(6), pp. 395-399, 2016.

[5] A. Laronche, L. Popescu, D. Benhamou, "An enhanced recovery programme after caesarean delivery increases maternal satisfaction and improves maternal-neonatal bonding: A case control study", Eur J Obstet Gynecol Reprod Biol, 210:212-216, 2017.

[6] I. J. Wrench, A. Allison, A. Galimberti, S. Radley, M. J. Wilson, "Introduction of enhanced recovery for elective caesarean section enabling next day discharge: a tertiary centre experience," Int J Obstet Anesth, 24(2), pp.124-130, 2015.

[7] S. J. Bowden, W. Dooley, J. Hanrahan, C. Kanu, S. Halder, C. Cormack, et al., "Fast-track pathway for elective caesarean section: a quality improvement initiative to promote day 1 discharge," BMJ Open Qual, 8(2), pp. e000465, 2019

[8] M. M. Killion, “Enhanced Recovery After Cesarean Birth”, MCN Am J Matern Child Nurs, 44(6), pp. $358,2019$.

[9] A. Jarraya, J. Zghal, S. Abidi, M. Smaoui, K. Kolsi, "Subarachnoid morphine versus TAP blocks for enhanced recovery after caesarean section delivery: A randomized controlled trial", Anaesth Crit Care Pain Med, 35(6), pp. 391-393, 2016.

[10] A. F. Peahl, R. Smith, T. R. B. Johnson, D. M. Morgan, M. D. Pearlman, "Better late than never: why obstetricians must implement enhanced recovery after cesarean", Am J Obstet Gynecol, 221(2), pp. 117.e1117.e7, 2019.

[11] U. Ituk, A. S. Habib, "Enhanced recovery after cesarean delivery," F1000Res, 7:F1000 Faculty Rev-513 Published 2018 Apr 27. doi:10.12688/f1000research.13895.1

[12] M. Hedderson, D. Lee, E. Hunt, K. Lee, F. Xu, A. Mustille, et al., "Enhanced Recovery After Surgery to Change Process Measures and Reduce Opioid Use After Cesarean Delivery: A Quality Improvement Initiative", Obstet Gynecol, 134(3):511-519, 2019.

[13] Nice Institute for Health and Care Excellence, "Clinical guideline 132 on caesarean section," Sep. 2019. [Online]. Available: https://www.nice.org.uk/guidance/cg132/chapter/1-Guidance\#care-ofthe-woman-after-cs. [accessed: Mar. 13, 2020].

[14] R. D. Wilson, A. B. Caughey, S. L. Wood, G. A. Macones, I. J. Wrench, J. Huang, et al., "Guidelines for Antenatal and Preoperative care in Cesarean Delivery: Enhanced Recovery After Surgery Society Recommendations (Part 1)," Am J Obstet Gynecol, 219(6), pp. 523.e1-523.e15, 2018.

[15] P. Parikh, I. Sunesara, S. Singh Multani, B. Patterson, E. Lutz, J. N. Martin Jr, "Intra-incisional liposomal bupivacaine and its impact on postcesarean analgesia: a retrospective study", J Matern Fetal Neonatal Med, 32(6), pp. 966-970, 2019

[16] L. Renfro, M. Todd, H. Mustafa, "Post-cesarean section analgesic safety and efficacy of EXPAREL (Liposomal Bupivacaine) infiltration locally versus Transversus Abdominis plane Infiltration. PCPC Study, "2017. [Online]. Available: https://clinicaltrials.gov/ProvidedDocs/95/NCT03377595/Prot_000.pdf. [Accessed: Mar. $16,2020]$.

[17] D. A. Delgado, B. S. Lambert, N. Boutris, P. C. McCulloch, A. B. Robbins, M. R. Moreno, et al., "Validation of Digital Visual Analog Scale Pain Scoring With a Traditional Paper-based Visual Analog Scale in Adults," J Am Acad Orthop Surg Glob Res Rev, 2(3), pp. e088, 2018.

[18] A. Kett, E. Cherot, "Enhanced Recovery Program Reduces Length of Stay \& Improves Value for Patients Undergoing Elective Cesarean Section," Obstet Gynecol,131, pp. 106S, 2018.

[19] E. Enabudoso, A. R. Isara, "Determinants of patient satisfaction after cesarean delivery at a university teaching hospital in Nigeria," IJGO, 114(3), pp. 251-254, 2011.

[20] I. Veličković, I. Budic, "Enhanced Recovery After Surgery," Front Med (Lausanne), 6, pp. 62, 2019.

[21] N. C. Teigen, N. Sahasrabudhe, G. Doulaveris, X. Xie, A. Negassa, J. Bernstein, et al., "Enhanced Recovery after Surgery (ERAS) at Cesarean to Reduce Postoperative Length of Stay: A Randomized Controlled Trial," Am J Obstet Gynecol, 22(4), pp. P372.E1-372.E10, 2019.

[22] G. A. Macones, A. B. Caughey, S. L. Wood, I. J. Wrench, J. Huang, M. Norman, et al., "Guidelines for postoperative care in cesarean delivery: Enhanced Recovery After Surgery (ERAS) Society recommendations (part 3)," Am J Obstet Gynecol, 221(3), pp. 247.e1-247.e9, 2019. 